\title{
VII. On algebraic equations of the fifth degree
}

\author{
James Cockle Esq. M.A.
}

To cite this article: James Cockle Esq. M.A. (1848) VII. On algebraic equations of the fifth

degree, Philosophical Magazine Series 3, 32:212, 50-53, DOI: $10.1080 / 14786444808645919$

To link to this article: http://dx.doi.org/10.1080/14786444808645919

曲 Published online: 30 Apr 2009.

Submit your article to this journal 준

Џll Article views: 3

Q View related articles $\asymp$ 


\section{[ 50 ] $]$}

VII. On Algebraic Equations of the Fifth Degree. By James Cockle, Esq., M.A., of Trinity College, Cambridge; Barrister-at-Law, of the Middle Temple*.

1. FEEL it right to premise that the object of this paper 1 is not the finite algebraic solution of any of the higher equations. Nevertheless it must be confessed that remarks of Dr. Peacock and Mr. Jerrard leave the question of the possibility of such solution still open. Mr. Bronwin appears to regard the point as, at all events, cloubtful. The advantages of such transformations as those discussed below are, that they enable us to confine our attention to a comparatively simple case, instead of our having to reason on the general equation. They are curious and interesting; they serve to mark the progress of theory and to indicate its direction. The first of them (the subject of the first article, and due originally to $\mathrm{Mr}$. Jerrard) is here shown to be connected with an important department of analytical geometry. It is capable of being performed with extraordinary facility - at least in one sense.

Let

$$
u^{5}+\mathrm{A}_{1} u^{4}+\mathrm{A}_{9} u^{8}+\mathbf{A}_{9} u^{2}+\mathrm{A}_{4} u+\mathrm{A}_{5}=0
$$

be the general equation of the fiflh degree. Also let

$$
v=x u+y u^{2}+z u^{3}+u^{4}
$$

and represent the transformed equation in $v$ by

$$
v^{5}+\mathrm{B}_{1} v^{4}+\mathrm{B}_{2} v^{3}+\mathrm{B}_{3} v^{2}+\mathrm{B}_{4} v+\mathrm{B}_{5}=0
$$

then this last equation may be put under the form

$$
\left(v+\frac{1}{5} B_{1}\right)^{5}+B_{2}^{\prime} z^{3}+B_{3}^{\prime} v^{2}+C_{4}\left(v+\frac{1}{5} B_{1}\right)+C_{5}=0,
$$

where

$$
\begin{aligned}
& \mathrm{B}_{2}^{\prime}=\mathrm{B}_{2}-\frac{2}{5} \mathrm{~B}_{1}^{2} ; \quad \mathrm{B}_{3}^{\prime}=\mathrm{B}_{3}-\frac{2}{5^{2}} \mathrm{~B}_{1}^{3} ; \\
& \mathrm{C}_{4}=\mathrm{B}_{4}-\frac{1}{5^{5}} \mathrm{~B}_{1}^{4} ; \quad \mathrm{C}_{5}=\mathrm{B}_{5}-\frac{1}{5^{5}} \mathrm{~B}_{1}^{5}-\frac{1}{5} \mathrm{~B}_{1} \mathrm{C}_{4} ;
\end{aligned}
$$

now, making

$$
w=v+\frac{1}{5} B_{1},
$$

we shall have transformed the given equation in $u$ into the following:

$$
w^{5}+\mathrm{C}_{4} w+\mathrm{C}_{5}=0, . \cdot . \cdot
$$

provided that $x, y$, and $\approx$ satisfy the conditions

$$
\mathrm{B}_{2}^{\prime}=0 \text {, and } \mathrm{B}_{3}^{\prime}=0 \text {. }
$$

* Communicated by the Author. 
Since these conditions are equations involving three undetermined quantities $x, y$ and $z$, they may with propriety be denoted by

and

$$
\begin{aligned}
& \phi(x, y, z)=0, \\
& \psi(x, y, z)=0
\end{aligned}
$$

respectively; and, since two dimensions of $x, y, z$ appear in (2.), and three in (3.), the former condition will in general represent a surface of the second, and the latter a surface of the third order.

I have in this work (S. 3. vol. xxviii. pp. 132, 133) already adverted to my own process for reducing equations of the fifth degree to a trinomial form. With what facility such reduction may be performed, at least so far as the decomposition of (2.) into linear factors is concerned, will be seen on referring to my papers on analytical geometry in the last and in the current volume of the Mechanics' Magazine.

It would not be difficult to show that when (2.) represents a hyperbolic paraboloid, a hyperboloid of one sheet, a cone, a cylinder, a pair of planes, a single plane, or a single straight line, then (2.) and (3.) can be satisfied simultaneously by real values of $x, y$, and $z$. In this case $\mathrm{C}_{4}$ and $\mathrm{C}_{5}$ will be real.

When (2.) represents a hyperboloid of two sheets, an elliptic paraboloid, an ellipsoid, a point, or an unreal surface, (2.) and (3.) cannot be so satisfied, and $\mathrm{C}_{4}$ and $\mathrm{C}_{5}$ will be in general both unreal.

Should $\mathrm{C}_{4}$ and $\mathrm{C}_{5}$, or either of them, prove to be unreal under the above assumption for $v$, it might be a question whether both those quantities would not take real values under some other assumption, such as

$$
v=x u^{\alpha}+y u^{\beta}+z u^{\gamma}+u^{\delta}
$$

but I an very strongly of opinion that they would not, and I an inclined to think that the reality of $C_{4}$ and $C_{5}$ depends upon the nature of the roots of the given equation in $u$. [There is perhaps some analogy between the question before us and that of the irreducible case in cubic equations.] If this be the correct view, no change of process can affect the final result; and we may apply, not only to Mr. Jerrard's, but to the above, and to every possible method of effecting this transformation, the remark of Sir W. R. Hamilton, that the coefficients of the transformed equation will often be unreal when those of the given one are real.

II. This appears to be the proper place for explaining an error into which I fell at page 132 of a previous volume of this work (vol. xxviii. just cited). I there omitted to notice that E 2 
the quantities $l$ ' and $l^{\prime \prime}$, being perfectly anbitrary, may be supposed to satisfy not only the equation (c.) but also the fol lowing,

$$
\Lambda^{\prime \prime \prime} x_{i}^{\lambda^{\prime \prime \prime}}+\Lambda^{\mathrm{iv}} x_{a}^{\lambda^{\mathrm{i}^{\mathrm{p}}}}=l^{\prime} x_{a}^{\lambda^{\prime}}+l^{\prime \prime} x_{a}^{\lambda^{\prime \prime}}, \quad \text {. . . }
$$

where $x_{4}$ is a root other than $x_{n}$. Let $x_{a}$ be $x_{n-1}$, then

$$
l_{n-1}=0 ; . . . \cdot, \cdot \cdot\left(\mathrm{e}^{l} .\right)
$$

and we must write $\left[l_{1} \ldots l_{n-2}\right]^{2}$ instead of $\left[l_{1} \ldots l_{n-1}\right]^{2}$ in equation (f.). But in this case, in order that we may satisfy

$$
\left[l_{1} \ldots I_{n-2}\right]^{2}=0 \text {. . . . . }
$$

without making the l's vinish, we have the condition

$$
n-2>1 \text {, }
$$

or $n=4$ at least; and ${ }_{2} \mathrm{Y}$ may be of such a form as to vender it necessary that $n$ be not less than 5 , which is the case in the transformation above considered. As to this, see page 395 of the last-mentioned volume, where I have pointed out the error here discussed, but not in such a manner as to make the foregoing explanation superfluous.

III. As connected with, and by way of concluding, this part of the subject, let

then (1.) gives

$$
w=\frac{w}{b}
$$

which will be of the form

$$
z^{\prime 5}+b^{4} \mathrm{C}_{4} w^{\prime}+b^{5} \mathrm{C}_{5}=0
$$

provided that

$$
\mathrm{r}^{15}+\mathrm{Dre}^{\prime}+\mathrm{D}^{5}=0, \quad . . . .
$$

$$
b=\left(\frac{\mathrm{C}_{5}}{\mathrm{C}_{4}^{5}}\right)^{\frac{1}{1-5}} \text {. }
$$

Now let

be a solution of $(4$.$) , then$

$$
w^{\prime}=\chi(\mathrm{D})
$$

$$
\mathrm{D}=\chi\left(w^{\prime}\right)
$$

will also be a solution: by combining these solations we obtain the functional equation

$$
x^{2}\left(w^{t}\right)=w^{\prime} \text {, or } x^{2}(D)=\mathrm{D} \text {; }
$$

and the same result might be obtained from any trinomial equation of the fifth degree-as I have already noticed (vol. xxviii, p. 133, note).

IV. At pages 190, 191 of the same (28.th) volume of the present work, there occur errors resembling those at pages 
132, 133, and which may be corrected in a similav manner. For this purpose let

$$
\mathrm{L}_{a}^{\mathrm{m}}=\Lambda^{\mathrm{m}}\left(x_{\bar{a}}^{\lambda^{\mathrm{m}}}-\frac{\gamma_{m}}{\gamma_{3}} x_{a}^{\lambda^{\prime \prime \prime}}\right)
$$

then it is, in substance, assumed (p. 190) that the equation

$$
\mathrm{L}_{a}^{\mathrm{iv}}+\mathrm{L}_{a}^{\mathrm{v}}+\ldots \mathrm{L}_{a}^{\mathrm{xi}}=l^{\prime} x_{a}^{\lambda^{\prime}}+l^{\prime \prime}\left(x_{a}^{\lambda^{\prime \prime}}-\frac{\gamma_{2}}{\gamma_{3}} x_{a}^{\lambda^{\prime \prime \prime}}\right) .
$$

is only true for $a=n$, that is to say, for the root $x_{n}$. But the two quantities $l^{\prime}$ and $l^{\prime \prime}$ may be taken so as to render this relation true, not only for $a=n$, but also for another value of $a$, which we may select at pleasure from among the suffixes of the roots. Let this other value be $n-1$, then (5.) will hold for the root $x_{n-1}$ and we have

$$
l_{n-1}=0 ;
$$

so that it becomes necessary in the group $(\alpha)$ to write $l_{n \rightarrow 2}$ in. stead of $1_{n-1}$, and consequently to change $(\alpha$.$) into$

$$
\left.\begin{array}{l}
{\left[l_{1}, l_{n-2}\right]^{2}=f_{1}^{2}(n-2)=0} \\
{\left[l_{1} \cdot l_{n-2}\right]_{2}^{2}=f_{2}^{2}(n-2)=0} \\
{\left[l_{1} \cdot l_{n-2}\right]^{3}=f^{3}(n-2)=0}
\end{array}\right\} \cdot \cdot \cdot \cdot\left(\alpha^{\prime} .\right)
$$

where $f^{a}(b)$ denotes a homogeneous function of the ath degree and of $b$ undetermined quantities. Hence we have

$$
n-2>3 \text {, or } n>5 \text {, }
$$

whence the least admissible value of $u$ is $6, \mathrm{or}$, in critical cases, 7 , and the equation of the fifth degree cannot (to say nothing of the additional difficulty occasioned by the occurrence of critical functions) be solved by means of the processes under our consideration, although those processes enable us to effect certain transformations of equations of degrees higher than the fifth (vol. xxviii. p. 395).

2 Church Yard Court, Temple,

November $18,1847$.

Postscript.-I venture to hope that the time is now approaching when we may expect a discussion of the physicomathematical problem connected with the Spheroidal Condition of Liquids. I regret that I have not had an opportunity of making an attempt, however humble, at its solution; and I would add that the enunciation of it' contained in a letter (signed $\mathbf{S}: \mathbf{X}$.) which I addressed to $\mathrm{Mr}$. Taylor from Great Oakley some two years since, and which will be found at pp. 568,569 of vol. xxvii. of this work, may be advantageously noodiffed.-J. C. 